\title{
Identification by mRNA Differential Display of Two Up-regulated Genes as Candidate Mediators of AIDS Dementia
}

\author{
Brigitte Wildemann, ${ }^{1}$ Juergen Haas, ${ }^{1}$ Karoline Stingele, ${ }^{1}$ Brigitte Storch-Hagenlocher, ${ }^{1}$ \\ Justin C. McArthur, ${ }^{2}$ Ted M. Dawson, ${ }^{3}$ and Valina L. Dawson ${ }^{3}$ \\ ${ }^{1}$ Department of Neurology, University of Heidelberg, Heidelberg, Germany \\ ${ }^{2}$ Department of Neurology, Johns Hopkins School of Medicine and Department of Epidemiology, \\ Johns Hopkins School of Hygiene and Public Health, Baltimore, MD, USA \\ ${ }^{3}$ Departments of Neurology, Neuroscience, and Physiology, Johns Hopkins University School of \\ Medicine, Baltimore, MD, USA \\ Contributed by S. Snyder. Accepted November 20, 2000
}

\begin{abstract}
Background: In the dementia associated with acquired immunodeficiency syndrome (AIDS), indirect pathomechanisms are important mediators of progressive neuronal injury and variable candidate molecules of potential pathogenetic importance have been identified.

Materials and Methods: In an attempt to characterize additional mediators of human immunodeficiency virus type 1 (HIV-1)-induced neurotoxicity in vivo we have adapted the mRNA differential display technique to monitor the gene expression pattern in postmortem cortical tissue from AIDS patients with $(n=7)$ and without $(n=8)$ cognitive impairment as well as from HIV-1 seronegative controls $(n=4)$.

Results: Out of 29 differentially expressed cDNAs, two cDNA clones had confirmed variation of transcriptional regulation as assessed by reverse Northern analysis and
\end{abstract}

gene-specific reverse transcription polymerase chain reaction (RT-PCR) and were up-regulated in the cortex of patients with AIDS dementia. Nucleotide sequence analysis of the two cDNAs identified known genes not previously associated with the pathogenesis of AIDS dementia, including the neurotrophin receptor tyrosine kinase receptor $\mathrm{B}(\operatorname{Trk} \mathrm{B})$ and the potassium channel human open rectifyer $\mathrm{K}^{+}$channel (ORK) homologous open reading frame (HOHOl).

Conclusions: The altered expression of these transcripts may contribute to AIDS dementia through the enhancement of microglial activation and immunologic nitric oxide synthase (iNOS) activity by abnormal neurotrophic regulation and interference with membrane excitability through disturbance of local ion homeostasis.

\section{Introduction}

The pathogenesis of the dementia associated with the acquired immunodeficiency syndrome (AIDS) is incompletely elucidated. The human immunodeficiency virus type 1 (HIV-1) mediates a productive infection of brain macrophages and microglia. Direct infection of neural cell types does not occur, although there is a drop in neuronal density as well as synaptic loss and dendritic simplification (1-6). The mechanisms involved in these neuronal changes appear to be indirect and multifactorial. The available evidence suggests that the release of various proinflammatory and neurotoxic molecules from activated macrophages and microglial cells are major determinants of brain damage (7-10). In most studies,

Address correspondence and reprint requests to: Valina L. Dawson, PhD, Departments of Neurology, Neuroscience, and Physiology, Johns Hopkins University School of Medicine, 600 North Wolfe Street, Carnegie 214, Baltimore, MD 21287, USA. Tel: 410-614-3359; Fax: 410-614-9568; e-mail: vdawson@ jhmi.edu mediators of potential importance in the pathogenesis of AIDS dementia, such as cytokines, chemokines, metalloproteinases, excitotoxic transmitters, and the neurotoxic effects of nitric oxide (NO) were studied selectively. Here, we have monitored the gene expression pattern in postmortem brain tissue obtained from HIV- 1 infected patients with and without dementia as well as from normal controls. Using reverse transcription polymerase chain reaction (RTPCR)-based mRNA differential display (11-13) we attempted to characterize candidate genes not previously associated with the HIV-1-induced disease process in the brain.

\section{Material and Methods Patients}

We tested tissue from a total of 19 patients. Fifteen patients were HIV-l seropositive and diagnosed with AIDS before death, and four individuals were HIV- 1 seronegative. Of the 15 patients with AIDS, 8 had no cognitive impairment and 7 had dementia. 
Dementia was categorized according to the Memorial Sloan Kettering (MSK) criteria $(14,15)$ and was mild (MSK 1 or 2) in three cases and severe (MSK 3 or 4) in four cases. Tissue was collected at autopsy, rapidly frozen in isopentane, and stored at $-70^{\circ} \mathrm{C}$. Cortical specimens were obtained from the frontal lobe in all cases. The presence of central nervous system (CNS) opportunistic infections or lymphoma was excluded by neuroimaging, cerebrospinal fluid analysis, and postmortem histopathologic evaluation of brain tissue sections. HIV-1 seronegative control specimens were obtained from patients without CNS lesions. The causes of death in control patients included pneumonia $(n=1)$ and trauma $(n=3)$. Postmortem delays in tissue collection were $8.75 \pm$ $2.75 \mathrm{hr}$ for HIV-l seronegative controls and $15.06 \pm$ $8.44 \mathrm{hr}$ for patients with AIDS. CD4 counts (number of cells per cubic millimeter) of HIV-1 positive individuals were $107.83 \pm 89.55$ (no dementia), $80.0 \pm$ 60.81 (mild dementia), and $55.0 \pm 60.75$ (severe dementia).

\section{Differential Display mRNA Analysis}

Differential display RT-PCR was carried out using tissue obtained from AIDS patients with severe dementia, no dementia, and normal controls. Total cellular RNA was extracted from frozen brain tissue using RNAzol (AGS, Heidelberg, Germany) according to the manufacturer's instructions. RNA was dissolved in $50 \mu$ l diethyl pyrocarbonate-treated water and incubated for $10 \mathrm{~min}$ at $37^{\circ} \mathrm{C}$ and for $5 \mathrm{~min}$ at $95^{\circ} \mathrm{C}$ with $10 \mathrm{U}$ ribonuclease-free deoxyribonuclease I (Boehringer, Mannheim, Germany) to remove chromosomal DNA contamination. Reverse transcription of $2 \mu \mathrm{g}$ total RNA was performed with Superscript II reverse transcriptase (Gibco BRL, Karlsruhe, Germany) using one of three different one base-anchored oligo-dT primers to subdivide mRNA into three subpopulations (16). Control reactions were performed in the absence of reverse transcriptase. One hundred nanograms of the cDNAs were then amplified in a $20-\mu$ l reaction in the presence of the respective 3 '-anchored oligo-dT primer $(2.5 \mu \mathrm{M}), 1$ out of 29 different 10-mer 5 '-arbitrary primers $(500 \mathrm{nM}), \mathrm{MgCl}_{2}(1.625 \mu \mathrm{M}), \mathrm{dNTPs}$ $(8 \mu \mathrm{M})$, and $1 \mathrm{U}$ Taq polymerase (AGS). In control reactions, water was substituted for cDNA. Thermal cycling conditions were as follows: $94^{\circ} \mathrm{C}(30 \mathrm{sec})$, $42^{\circ} \mathrm{C}(60 \mathrm{sec}), 72^{\circ} \mathrm{C}(30 \mathrm{sec})$ for 40 cycles and a final extension step at $72^{\circ} \mathrm{C}$ for $5 \mathrm{~min}$. PCR products were loaded on a $12.5 \%$ polyacrylamide gel (Pharmacia, Freiburg, Germany) and detected by silver staining. Differentially regulated amplification products were defined as those bands that were either present or absent in cDNA subpopulations derived from AIDS patients with severe demenntia as compared to nondemented AIDS patients or normal controls. Further characterization of selected bands demonstrating differential expression was carried out if the amplification pattern was reproduced with a different
CDNA preparation in a second PCR reaction. PCR products of interest were cut out from the gel, eluted with $20 \mu$ l sterile water, and reamplified by PCR in a $50 \mu \mathrm{l}$ reaction using the appropriate primer set. The reaction mixture contained $2 \mathrm{mM} \mathrm{MgCl}_{2}, 100$ $\mu \mathrm{M}$ dNTP, $1.25 \mu \mathrm{M} 3$ '-anchored oligo-dT primer, 250 nM 5'-arbitary primers, and 1 U AmpliTaq Gold (Applied Biosystems, Weiterstadt, Germany). Reamplification PCR proceeded over 45 cycles. Cycling conditions were as described for differential display RT-PCR except an initial denaturation step at $95^{\circ} \mathrm{C}$ for $8 \mathrm{~min}$. Reamplified cDNA fragments were subcloned into the plasmid vector pCR II using the a TA Cloning Kit (Invitrogen, Groningen, Netherlands). Inserted cDNAs of correct size were used for DNA slot blot analysis and nucleotide sequence assessment.

\section{DNA Slot Blot Analysis (Reverse Northern Analysis)}

Subcloned cDNA fragments were heat denatured and approximately $5 \mu \mathrm{g}$ was applied in duplicate to a nylon membrane with the use of a Minifold 1-Spot Blotter (Schleicher \& Schuell, Dassel, Germany). Following baking for $1 \mathrm{hr}$ at $80^{\circ} \mathrm{C}$ in a vacuum oven, membranes were equilibrated in $5 \times$ SSC, $50 \%$ formamide, $1 \%$ SDS, and $5 \%$ blocking powder. For reverse Northern hybridization digoxigenin (dig)11-dUTP-labeled cDNA was generated with a digcDNA Synthase Kit (Boehringer Mannheim) from $5 \mu \mathrm{g}$ of RNA preparations derived from cortical tissue specimens adjacent to those used for mRNA differential display analysis. Heat-denatured cDNA prepared from cortical tissue of nondemented and severely demented AIDS patients and from normal controls was added separately to the hybridization solutions containing one of the duplicate dot blotted membranes. Hybridization was carried out for $16 \mathrm{hr}$ at $42^{\circ} \mathrm{C}$. Membranes were washed twice in $0.1 \times$ SSC, $0.1 \%$ SDS at $68^{\circ} \mathrm{C}$. Colorimetric detection was performed with a dig-Detection Kit (Boehringer Mannheim).

\section{Nucleotide Sequence Determination}

Both reamplified fragments and subcloned inserts with confirmed differential expression as determined by reverse Northern analysis were purified using Qiaquick spin columns (Qiagen, Düsseldorf, Germany). Sequencing was carried out by the fluorescent dideoxy chain termination method utilizing an automated DNA sequencer (ABIPrism 310, Applied Biosystems). The nucleotide sequences obtained were compared with known sequences by searching the GenBank and EMBL databases with BLAST algorithms.

\section{Quantitative RT-PCR}

Differential gene expression was further confirmed by SYBR Green real-time quantitative PCR and total RNA derived from brain tissue of all patient groups was tested. Two micrograms of the RNA preparation, which had also been used for the reverse Northern analysis, was reverse transcribed with 
random hexamers using the GeneAmp RNA Core Kit (Applied Biosystems). Primers for the sequences of interest were designed with the Primer Express software (Applied Biosystems). Detection of $\beta$-actin mRNA was used to normalize the expression of target mRNAs. $\beta$-Actin-specific primers were provided by Applied Biosystems. Coamplification of $\beta$-actin cDNA and target cDNAs were carried out in 3-fold parallel reactions using SYBR Green reagents (Applied Biosystems). A negative control was included in each reaction set. Reaction mixtures contained $200 \mathrm{ng}$ cDNA, $3 \mathrm{mM} \mathrm{MgCl}, 250 \mu \mathrm{g}$ dNTPs, $300 \mathrm{nM}$ of each primer, $1.25 \mathrm{U}$ AmpliTaq Gold ${ }^{\mathrm{TM}}$, and $3 \mathrm{U}$ AmpErase in a total volume of $30 \mu \mathrm{l}$. Thermal cycling proceeded in a GeneAmp 5700 Sequence Detection System (Applied Biosystems) with $95^{\circ} \mathrm{C}$ (10 min) followed for 40 cycles with $60^{\circ} \mathrm{C}(1 \mathrm{~min})$, and $95^{\circ} \mathrm{C}(15 \mathrm{sec})$. The quantity of target cDNAs was calculated with the use of the $\Delta \Delta \mathrm{Ct}$ method as described in the GeneAmp 5700 Sequence Detection System user's manual (Applied Biosystems). Results are defined as the target gene expression normalized against the $\beta$-actin gene expression in cortical tissue from patients with severely, mildly, and nondemented AIDS patients relative to the respective gene expression in cortical tissue from normal controls.

\section{Statistical Analysis}

The expression of selected genes as assessed by quantitative RT-PCR was analyzed by using Fisher's least significance difference test.

\section{Results}

\section{Differential Display mRNA Analysis}

We performed differential display RT-PCR with a total of 77 primer combinations. Twenty-nine amplification reactions were carried out with the one-base anchored T11A oligo-dT primer; 25 and 23 reactions were performed with one-base anchored TllC or T11G oligo-dT primers, respectively. We identified 29 PCR products that were differentially expressed between brain tissues obtained from severely demented and nondemented AIDS patients or normal controls. Figure 1 shows one representative PCR product that was reproducibly present in cortical samples from AIDS patients with severe dementia and less prominent in the cortex of two AIDS patients as compared to cortical specimes from normal controls.

\section{Reverse Northern Analysis}

Reverse Northern analysis was performed to confirm the gene regulation patterns observed in the mRNA differential display study. From the 29 differentially expressed PCR products, 25 bands were successfully reamplified and screened by direct nucleotide sequence analysis. Eight fragments turned out to be artifacts and were not further assessed. The remaining 17 fragments were subcloned to be used as probes in

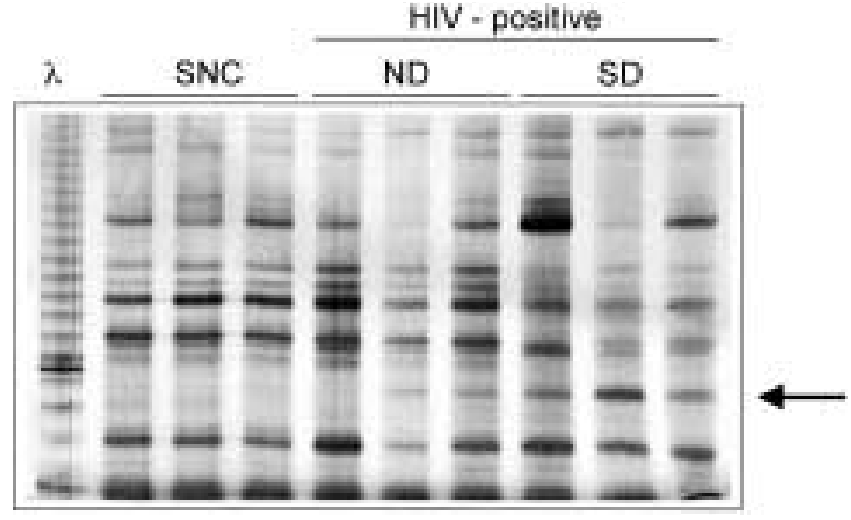

Fig. 1. Differential display RT-PCR comparing mRNAs extracted from cortical tissue obtained at autopsy from HIV-1 seronegative controls (SNC, lanes 2 through 4) and from HIV-1 infected patients with no dementia (ND, lanes 5 through 7) or severe dementia (MSK 3 or 4) (SD, lanes 8 through 10). $\lambda$ is the DNA length standard. PCR products were loaded on a $12.5 \%$ polyacrylamide gel and detected by silver staining. The illustrated primer combination identified one distinct fragment, which was up-regulated in the cortex of three demented and two nondemented HIV-1 infected subjects (arrow). Primers included T11G as $3^{\prime}$ anchor primer and 5'-AAGCTTACGG TACAC-3' as random primer.

DNA slot blots prepared with cDNAs from cortical tissues of nondemented and severely demented AIDS patients and from normal controls. Three of the 17 subcloned PCR products yielded hybridization signals that reproduced the expression patterns obtained by mRNA differential display (Fig. 2). The remaining 12 reamplified and subcloned PCR fragments generated discordant hybridization patterns and were not studied further.

\section{Sequence Homology}

Sequence analysis of the three cloned cDNA fragments with confirmed differential expression revealed
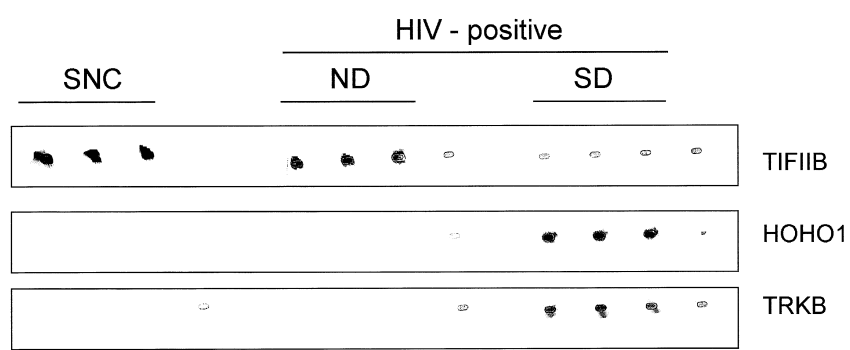

Fig. 2. Reverse Northern analysis confirming alternate gene regulation patterns for three differential display bands identified as TIFIIB, HOHOI, and TrkB by nucleotide sequence analysis. DNA slot blots prepared with the three fragments were probed with cDNAs derived from the cortex of SNCs and from HIV-1 infected patients with ND or SD (MSK 3 or 4). Consistent with differential display RT-PCR reverse Northern analysis demonstrates down-regulation of TIFIIB and up-regulation of $\mathrm{HOHOI}$ and TrkB in brain tissue samples from AIDS patients with SD as compared to AIDS patients with ND and SNCs. 
homologies with three distinct genes. The three gene fragments were highly homologous to tyrosine kinase receptor B (TrkB), the potassium channel coding gene human open rectifier $\mathrm{K}^{+}$channel (ORK)-homologous open reading frame (HOHOl), and the general transcription initiation factor IIB (TIFIIB).

\section{Quantitative RT-PCR}

The mRNA expression of the three genes identified by nucleotide sequencing was assessed by quantitative SYBR Green real-time PCR using primers with specificity for human TrkB, HOHOl, and TIFIIB. Total RNA derived from cortical tissue specimens of all patient groups was included in the analysis. Results are outlined in Fig. 3. There was a 4l-fold increase in TrkB mRNA in the cortex of severely demented AIDS patients as compared to the cortex of HIV-l seronegative persons. TrkB mRNA expression was also increased in brain tissue of AIDS patients without or with mild cognitive impairment, although it was less pronounced (9-fold and 22-fold, respectively). HOHO-1 gene transcripts were moderatly elevated in cortical tissue of all patients with AIDS as compared to HIV-1 seronegative controls. Increases were 6.1-fold (nondemented AIDS patients), 5.7-fold (mildly demented AIDS patients), and 9.4-fold (severely demented AIDS patients). Quantitative RT-PCR of TIFIIB mRNA was discordant with the results of mRNA differential display and reverse Northern analysis, and did not confirm the down-regulation of transcript levels. The amount of TIFIIB was similar in the cortex of AIDS patients with severe cognitive dysfunction as compared to the control group (1.07-fold) and mildly down-regulated in the remaining patients $(0.66$-fold and 0.5-fold in AIDS patients without or with mild cognitive impairment).

\section{Discussion}

Using the mRNA differential display technique and 77 primer combinations, we identified 29 cDNAs that reproducibly showed different expression patterns between brain tissues from AIDS patients with severe dementia and nondemented AIDS patients or HIV-1 seronegative persons. Differing transcriptional regulation was confirmed for three cDNAs by reverse Northern analysis. We identified from these three bands three known genes, the tyrosine kinase receptor TrkB for the neurotrophins brain-derived neurotrophic factor (BDNF) and neurotrophin-4/5 (NT-4/5), the potassium channel HOHOl, and the general transcription initiation factor TIFIIB. Up-regulation of TrkB and HOHO-1 in the cortex of severely demented AIDS patients and less pronounced in the brain of nondemented and mildly demented AIDS patients was reproduced by quantitative RT-PCR with selected primers. Quantitative RT-PCR, however, did not
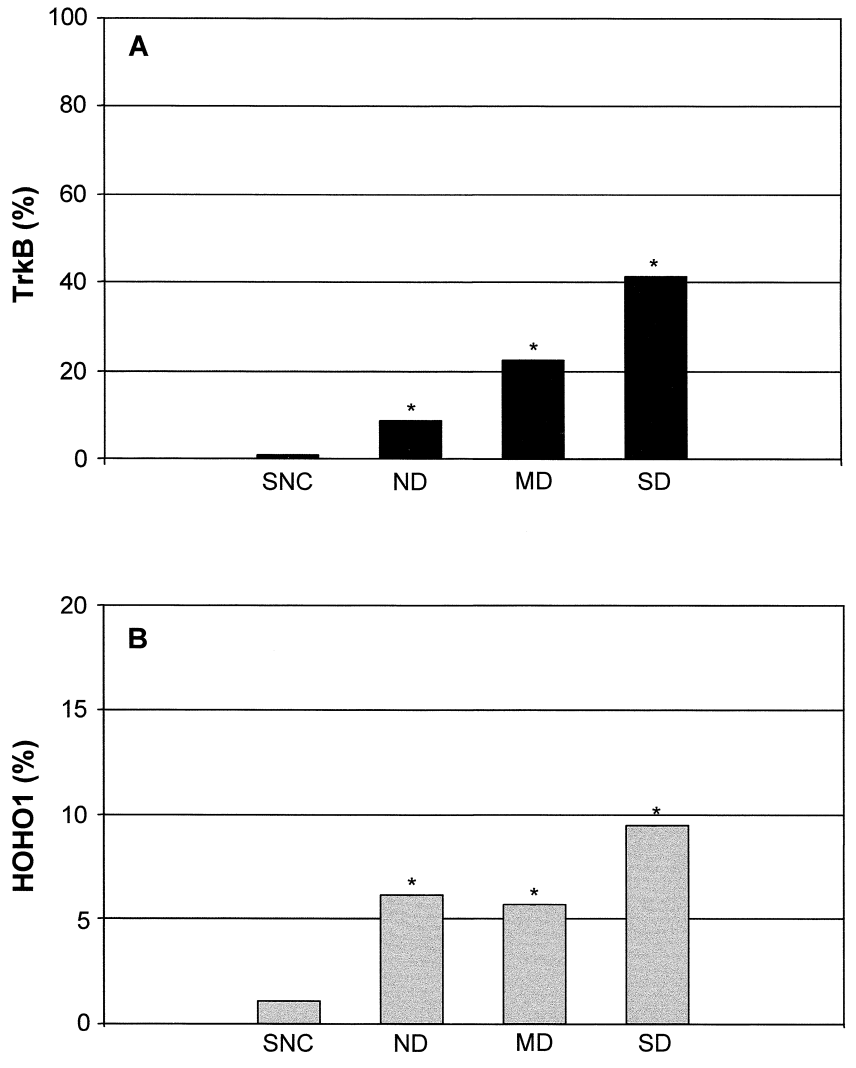

Fig. 3. Quantitative SYBR Green real-time PCR with TrkB and HOHOI specific primers. Amplification was carried out using cortical tissue obtained at autopsy from SNCs $(n=4)$ and from AIDS patients with ND $(n=8)$, mild dementia (MD, $n=3)$, and SD $(n=4)$. TrkB and HOHOI mRNA levels were normalized against $\beta$-actin mRNA levels and their expression in the cortex of AIDS patients with ND, MD, and SD is illustrated relative to the cortex of SNCs. (A) Expression of TrkB mRNA. TrkB mRNA levels are 41-fold increased in the cortex from AIDS patients with SD as compared to brain tissue of SNCs ( $p=.0001$, Fisher's least significance difference test). TrkB transcription is 22-fold and 9-fold up-regulated in the brains of AIDS patients with MD $(p<.0001)$ and ND $(p<$ $.001)$. TrkB specific primers were 5'-CCTGAAGGATGCC AGTGACAA-3' (forward) and 5'-CTCCACGCAGACGCCATA3' (reverse). (B) Expression of HOHOI mRNA. HOHOI levels are 9.4-fold, 5.7-fold, and 6.1-fold increased in the cortex of patients with SD $(p<.001), \operatorname{MD}(p=.01)$, and ND $(p<.001)$ as compared to brain tissue of SNCs. HOHOI specific primers were 5'-GGTGCTGGGCTACTT GCTCT-3' (forward) and 5'-ATAGGGCAGCTCCACCGAG-3' (reverse). TIFIIB-specific quantitative PCR did not confirm down-regulation of the transcript and is not shown. TIFIIB-specific primers were 5'-CATATAGCCCGTAAAGCTGTGGAA-3' (forward) and 5'-GCAACACCAGCAATATCTCCAAT-3' (reverse).

confirm alternate transcriptional regulation of TIFIIB, which was present at lower levels in cortical tissue of severely demented AIDS patients according to mRNA differential display and reverse Northern analysis. The relatively low number of genes with confirmed differential expression underlines the importance of stringent verification procedures to prove the specificity of results obtained by the mRNA differential display technique. 
This may be even more important when assessing gene expression in whole tissue rather than in cell lines cultured under uniform conditions. In our study, drawbacks of the technique were failure of some primer combinations to yield representative patterns of bands and unsuccessful reamplification and sequencing of cDNA fragments resulting from contaminating unrelated DNA sequences as previously described $(12,13,18)$. In addition, the missing detection of weak to moderate alterations in expression of selected genes between test samples and/or the absence of low-level transcripts within the display may account for the low number of identified candiate genes. Furthermore, these technical limitations most likely explain why we did not detect up-regulation of gene transcripts with demonstrated importance in the pathogenesis of AIDS dementia such as TNF- $\alpha$ and inducible nitric oxide synthase (iNOS) (18-21). Advanced technologies, such as cDNA microarray analysis, are promising tools for a more comprehensive assessment of the HIV-1-induced gene expression pattern within the CNS (22).

The most important finding of this study is the marked up-regulation of TrkB mRNA in the cortex of severely demented AIDS patients. Recent evidence suggests that the interaction of TrkB with its ligands BDNF and NT-4/5 mediates an extremely potent endogenous neuroexcitatory action (23). BDNF and other neurotrophins are known for their trophic effects and the induction of TrkB expression could merely reflect a compensatory mechanism to prevent progressive neuronal loss. However, abnormal neurotrophic regulation may also affect neuronal survival and promote excitotoxic neuronal injury $(24,25)$. One mediator of neurotrophin-induced excitotoxicity is the modulation of both neuronal and immunologic NO synthase (nNOS, iNOS) activity (26-28). Our previous studies have demonstrated that iNOS is markedly elevated in the cortex of patients with severe AIDS dementia and its induction via the viral glycoprotein gp4l is linked to HIV-1related cognitive dysfunction $(19,21)$. In the cortex of HIV-1-infected individuals, iNOS expression occurs predominantly in microglial cells (29). Interestingly, in AIDS dementia, but not in Alzheimer's disease, expression of both TrkB and BDNF is induced in reactive astrocytes and activated microglial cells, respectively $(30,31)$. Because BDNF and NT4 promote microglial activation in vitro $(32,33)$, continous high-level coexpression of neurotrophins and TrkB may contribute to the marked stimulation of glial cells and macrophages in HIV-1-infected brains, which is know to affect the degree of cognitive decline (34). This paracrine effect could also potentiate the iNOS induction associated with advanced AIDS dementia that may in turn limit the neuroprotective potential of the TrkB/BDNF/NT$4 / 5$ pathway. The interference of iNOS induction with regenerative mechanisms provides additional evidence that inhibitors of iNOS could exert therapeutic effects in HIV-1-associated cognitive decline.

HOHO 1, the second up-regulated gene, was first isolated from human brain cDNA and is identical in its coding sequence to TWIK l(tandem of P domains in a weak inwardly rectifying $\mathrm{K}^{+}$channel), which belongs to a novel structural and functional group of potassium channels (35). In both humans and mice its expression is particularly abundant in brain and heart, and within murine brain high levels are present in cerebellar granule cells, brainstem, hippocampus, and cerebral cortex (36-38). TWIK 1 behaves as an inwardly rectifying potassium channel and is though to be involved in the control of background $\mathrm{K}^{+}$membrane conductances $(36,37)$. In our study, levels of $\mathrm{HOHO} 1 \mathrm{mRNA}$ were moderately increased within the cortex of HIV-1-infected patients with peak levels in brain tissue of severely demented individuals. Although the role of HOHOl mRNA up-regulation in AIDS related cognitive dysfunction remains speculative, the modification of $\mathrm{K}^{+}$ currents may occur early following HIV-1 invasion of the CNS and may have consequences for neuronal function through disturbance of local ion homeostasis. Consistent with this hypothesis, several studies have shown that the HIV-1 coat proteins gp 160 and gp 120 as well as the regulatory protein Nef modify the $\mathrm{K}^{+}$conductance of various potassium channels in both lymphocyte and glial cell lines or neurons (39-43). Furthermore, the release of cytokines and other immune mediators affect $\mathrm{K}+$ currents in astrocytes $(44,45)$ and may additionally impair basic glial and neuronal properties. Further characterization of HIV-1-induced alterations of potassium channel function offers important perspectives for the development of novel pharmacologic strategies against the emergence of AIDS-related cognitive dysfunction.

In conclusion, using mRNA differential display analysis we identified the TrkB/BDNF/NT- $4 / 5$ pathway and the inward rectifying potassium channel HOHO- 1 as two novel candidate mediators associated with the complex disease process of AIDS dementia. Abnormal neurotrophic regulation may enhance excitotoxic pathomechanisms via sustained activation of microglia and macrophages within the brain of HIV-1-infected individuals and alterations of potassium channel function may affect the pathogenesis of AIDS dementia through interference with membrane excitability of various cell types. Future studies will have to define in more detail the in vivo relevance of these findings and their potential pharmacologic implications.

\section{Acknowledgments}

This study was supported by the Heinz Ansmann Foundation for AIDS Research, Heinrich Heine University, Duesseldorf, Germany and the USPHS Grant NS 26643. 


\section{References}

1. Ketzler S, Weis S, Haug H, Budka H. (1990) Loss of neurons in the frontal cortex in AIDS brains. Acta Neuropathol. (Berl.) 80: $92-94$.

2. Everall IP, Luthert PJ, Lantos PL. (1991) Neuronal loss in the frontal cortex in HIV infection. Lancet 337: 1119-1121.

3. Wiley CA, Masliah E, Morey M, et al. (1991) Neocortical damage during HIV infection. Ann. Neurol. 29: 651-657.

4. Masliah E, Ge N, Morey M, DeTeresa R, Terry RD, Wiley CA. (1992) Cortical dendritic pathology in human immunodeficiency virus encephalitis. Lab. Invest. 66: 285-291.

5. Masliah E, Heaton RK, Marcotte TD, et al. (1997) Dendritic injury is a pathological substrate for human immunodeficiency-related disorders. Ann. Neurol. 42: 963-972.

6. Wiley CA, Achim CL, Christophersen C, et al. (1999) HIV mediates a productive infection of the brain. AIDS 13: 2005-2059.

7. Epstein LG, Gendelman HE. (1993) Human immunodeficiency virus type 1 infection of the nervous system: pathogenetic mechanisms. Ann. Neurol. 33: 429-236.

8. Lipton SA, Gendelman HE. (1995) Seminars in medicine of the Beth Israel Hospital, Boston. Dementia associated with the acquired immunodeficiency syndrome. N. Engl. J. Med. 332: 934-940.

9. Lipton SA. (1997) Neuropathogenesis of acquired immunodeficiency syndrome dementia. Curr. Opin. Neurol. 10: 247253.

10. McArthur JC, Sacktor N, Selnes O. (1999) Human immunodeficiency virus-associated dementia. Sem. Neurol. 19: 129150.

11. Liang P, Pardee AB. (1992) Differential display of eukaryotic messenger RNA by means of the polymerase chain reaction. Science 257: 967-971.

12. Bauer D, Mueller H, Reich J, et al. (1993) Identification of differentially expressed mRNA species by an improved display technique (DDRT-PCR). Nucl. Acids Res. 21: 4272-4280.

13. Liang P, Averboukh L, Pardee AB, (1993) Distribution and cloning of eukaryotic mRNAs by means of the differential display: refinements and optimization. Nucl. Acids Res. 21: 3269-3275.

14. Price RW, Brew BJ. (1998)The AIDS dementia complex. J. Infect. Dis. 158: 1079-1083.

15. Janssen RS, Cornblath DR, Epstein LG, McArthur JC, Price RW. (1991) Nomenclature and research case definitions for neurological manifestations of human immunodeficiency virus type-1 (HIV-1) infection. Report of a Working Group of the American Academy of Neurology AIDS Task Force. Neurology 41: 778-785.

16. Liang P, Zhu W, Zhang X, et al. (1994) Differential display using one-base anchored oligo-dT primers. Nucl. Acids Res. 22: 5763-5764.

17. Callard D, Lescure B, Mazzolini L. (1994) A method for the elimination of false positives generated by the mRNA differential display technique. BioTechniques 16: 1096-1103.

18. Wesselingh SL, Power C, Glass JD, et al. (1993) Intracerebral cytokine messenger RNA expression in acquired immunodeficiency syndrome dementia. Ann. Neurol. 33: 576-582.

19. Adamson DC, Wildemann B, Sasaki M et al. (1996) Immunologic NO synthase: elevation in severe AIDS dementia and induction by HIV-1 gp4l. Science 274: 1917-1921.

20. Wesselingh SL, Takahashi K, Glass JD, McArthur JC, Griffin JW, Griffin DE. (1997) Cellular localization of tumor necrosis factor mRNA in neurological tissue from HIV-infected patients by combined reverse transcriptase/polymerase chain reaction in situ hybridization and immunohistochemistry. $J$. Neuroimmunol. 74: 1-8.

21. Adamson DC, McArthur JC, Dawson TM, Dawson VL. (1999) Rate and severity of HIV-associated dementia (HAD): correlations with gp4l and iNOS. Mol. Med. 5: 98-109.

22. Whitney LW, Becker KG, Tresser NJ, et al. (1999) Analysis of gene expression in multiple sclerosis lesions using cDNA microarrays. Ann. Neurol. 46: 425-428.
23. Kafitz KW, Rose CR, Thoenen H, Konnerth A. (1999) Neurotrophin-evoked rapid excitation through TrkB receptors. Nature 401: 918-921.

24. Koh JY, Gwag BJ, Lobner D, Choi DW. (1995) Potentiated necrosis of cultured cortical neurons by neurotrophins. Science 268: 573-575.

25. Park EC, Jou I, Gwag BJ.(1998) Nerve growth factor potentiates the oxidative necrosis of striatal cholinergic neurons. Neuroreport 9: 687-690.

26. Samdani AF, Newcamp C, Resink A, et al. (1997) Differential susceptibility to neurotoxicity mediated by neurotrophins and neuronal nitric oxide synthase. J. Neurosci. 17: 4633-4641.

27. Klocker N, Cellerino A, Bahr M. (1998) Free radical scavenging and inhibition of nitric oxide synthase potentiates the neurotrophic effects of brain-derived neurotrophic factor on axotomized retinal ganglion cells in vivo. J. Neurosci. 18: $1038-1046$.

28. Klocker N, Kermer P, Gleichmann M, Weller M, Bahr M. (1999) Both the neuronal and inducible isoforms contribute to upregulation of retinal nitric oxide synthase activity by brain-derived neurotrophic factor. J. Neurosci. 10: 85178527.

29. Vincent A, De Groot CJ, Lucassen PJ, et al. (1999) Nitric oxide synthase expression and apoptotic cell death in brains of AIDS and AIDS dementia patients. AIDS 13: 317-326.

30. Soontornniyomkij V, Wang G, Pittman CA, Wiley CA, Achim CL. (1998) Expression of brain-derived neurotrophic factor protein in activated microglia of human immunodeficiency virus type 1 encephalitis. Neuropathol. Appl. Neurobiol. 24: 453460.

31. Soontornniyomkij V, Wang G, Pittman CA, Hamilton RL, Wiley CA, Achim CL. (1999) Absence of brain-derived neurotrophic factor and trkB immunoreactivity in glia of Alzheimer's disease. Acta Neuropathol. (Berl.) 98: 345-348.

32. Elkabes S, DiCicco-Bloom EM, Black IB. (1996) Brain microglia/macrophages express neurotrophins that selectively regulate microglial proliferation and function. J. Neurosci. 16: 2508-2521.

33. Nakajima K, Kikuchi Y, Ikoma E, et al. (1998) Neurotrophins regulate the function of cultured microglia. Glia 24: 272-289.

34. Glass JD, Fedor H, Wesselingh SL, et al. (1995) Immunocytochemical quantitation of HIV in the brain: Correlations with HIV-associated dementia. Ann. Neurol. 37: 755-762.

35. Goldstein SAN, Wang KW, Han N, Pausch MH. (1998) Sequence and function of the two $\mathrm{P}$ domain potassium channels: implications of an emerging superfamily. J. Mol. Med. 76: 13-20.

36. Lesage F, Guillemare E, Fink M, et al. (1996) TWIK-1, a ubiquitous human weakly inward rectifying $\mathrm{K}+$ channel with a novel structure. $E M B O$ J. 15: 1004-1011.

37. Lesage F, Lauritzen I, Duprat F, et al. (1997) The structure, function and distribution of the mouse TWIK-1 K+ channel. FEBS Lett. 402: 28-32.

38. Arrighi I, Lesage F, Scimeca JC, Carle GF, Barhanin J. (1998) Structure, chromosome localization, and tissue distribution of the mouse TWIK K+ channel. FEBS Lett. 425: 310-316.

39. Werner T, Ferroni S, Saermark T, et al. (1991) HIV-1 Nef protein exhibits structural and functional similarity to scorpion peptides interacting with $\mathrm{K}+$ channels. AIDS 5: 13011308.

40. Bubien JK, Benveniste EN, Benos DJ. (1995) HIV-gp120 activates large-conductance apamin-sensitive potassium channels in rat astrocytes. Am. J. Physiol. 268: C1440-1449.

41. Kort JJ, Jalonen TO. (1998) The nef protein of the human immunodeficiency virus type 1 (HIV-1) inhibits a largeconductance potassium channel in human glial cells. Neurosci. Lett. 25 1: 1-4.

42. Dellis O, Bouteau F, Guenounou M, Rona JP. (1999) HIV-1 gp 160 decreases the $\mathrm{K}+$ voltage-gated current from Jurkat E6.1 T cells by up-phosphorylation. FEBS Lett. 443: 187-191.

43. Zegarra-Moran O, Rasola A, Rugolo M, Porcelli AM, Rossi B, Galietta LJV.(1999) HIV-1 nef expression inhibits the 
activity of a $\mathrm{Ca} 2+$-dependent $\mathrm{K}+$ channel involved in the control of the resting potential in CEM lymphocytes. J. Immunol. 162: 5359-5366.

44. Koller H, Siebler M, Pekel M, Muller HW. (1993) Depolarization of cultured astrocytes by leukotriene B4. Evidence for the induction of a $\mathrm{K}+$ conductance inhibitor. Brain Res. 612: 28-34.

45. Koller H, Allert N, Oel D, Stoll G, Siebler M. (1998) TNF alpha induces a protein kinase $\mathrm{C}$-dependent reduction in astroglial K+ conductance. Neuroreport 9: 1375-1378. 